\title{
Tendon Allograft for Repair of the Medial Collateral Ligament of the Knee: A Case Report
}

\author{
Konstantinos C. Xarchas ${ }^{1}{ }^{*}$, Panagiotis Givissis ${ }^{2}$ \\ ${ }^{1} 1^{\text {st }}$ Orthopaedic Department, Athens General Hospital G Gennimatas, Athina, Greece \\ ${ }^{2}$ Aristotelion University, Thessaloniki, Greece \\ Email: *drkcxr@yahoo.com
}

How to cite this paper: Xarchas, K.C. and Givissis, P. (2016) Tendon Allograft for Repair of the Medial Collateral Ligament of the Knee: A Case Report. Open Journal of Orthopedics, 6, 315-320.

http://dx.doi.org/10.4236/ojo.2016.610041

Received: April 11, 2016

Accepted: October 11, 2016

Published: October 14, 2016

Copyright $\odot 2016$ by authors and Scientific Research Publishing Inc. This work is licensed under the Creative Commons Attribution International License (CC BY 4.0).

http://creativecommons.org/licenses/by/4.0/

\begin{abstract}
In the rare cases with serious damage of the Medial Collateral Ligament (MCL) of the knee requiring surgical treatment, ligament remnants may be inadequate for a good repair. In such cases, reconstruction should be performed and technical options may be limited. We used an Achilles tendon allograft and applied it using the Pulvertaft weave technique for tendon repair. We found no previous reports of allograft application for MCL repair though the technique has been extensively used for Anterior Cruciate Ligament reconstruction.
\end{abstract}

\section{Keywords}

Knee, Medial Collateral Ligament, Allograft

\section{Introduction}

The Medial Collateral Ligament of the knee (MCL) is one of its major stabilizers. It has two parts, the superficial and the deep one and offers medial stabilization when valgus forces are applied on the knee. The gravity of the MCL injuries may vary between a simple strain (Grade 1) and a complete rapture (Grade 3). Most isolated injuries of the MCL are treated non operatively [1]. In some cases of complete rupture though, the knee can be followed by injuries of the medial meniscus or/and the anterior cruciate ligament and becomes very unstable. In such cases, surgical repair is indicated and reconstruction may be the only option.

\section{Case Report}

A fifty-year old man sustained a rotational injury of his right knee after falling from a small height. On initial examination X-rays revealed no fracture, but clinically the knee 
was swollen and very tender over its medial side. A Robert-Jones bandage was applied, the leg was elevated and non-weight bearing was advised for two weeks at which time he was reexamined. A Grade III postero-medial knee instability was now clear on examination (wide and almost nonstop opening of the medial compartment on valgus stressing). An MRI scan revealed complete rupture of the medial collateral ligament with detachment of both insertions and also mid-substance damage. It also revealed an incomplete rupture of the ACL. On these findings surgical correction of the medial compartment was decided.

Under GA and tourniquet application the medial side and posterior corner of the knee was explored. Both parts of the MCL were completely destroyed and the remnants of the ligaments were frail (Figure 1). First the posterior corner was stabilized with advancement and suturing of the capsule. Through the same incision with simple elevation of the ruptured medial collateral ligament the medial meniscus and ACL were inspected (Figure 2). The meniscus was detached in its periphery but otherwise intact and the ACL was in continuity but loose. Because of the extensive MCL damage we decided to augment the repair with a freeze dried Achilles tendon allograft (Figure 3). A part of the graft was properly shaped and weaved through the superficial-deep ligament complex (Pulvertaft technique). Both insertions were stabilized to the femur and tibia by the use of bone anchors and in maximal tension. The medial meniscus was sutured to the deep ligament and the ACL was not further addressed (Figure 4 and Figure 5).

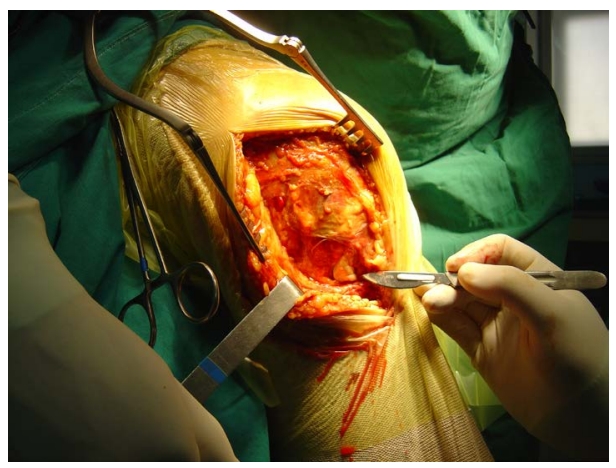

Figure 1. On initial dissection superficial MCL completely detached.

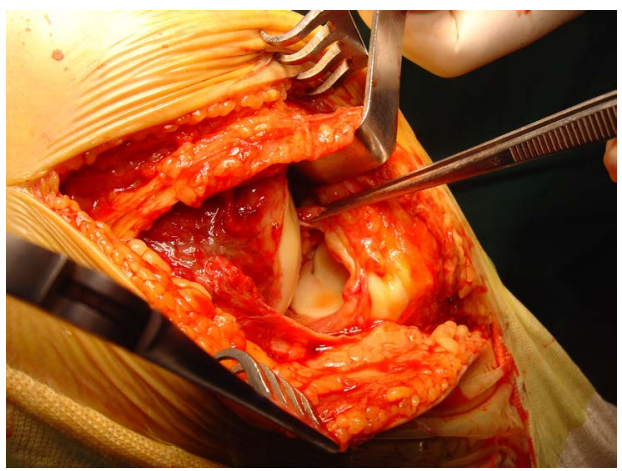

Figure 2. Deep MCL ruptured, medial and posterior capsule torn, medial meniscus detached from deep MCL. 


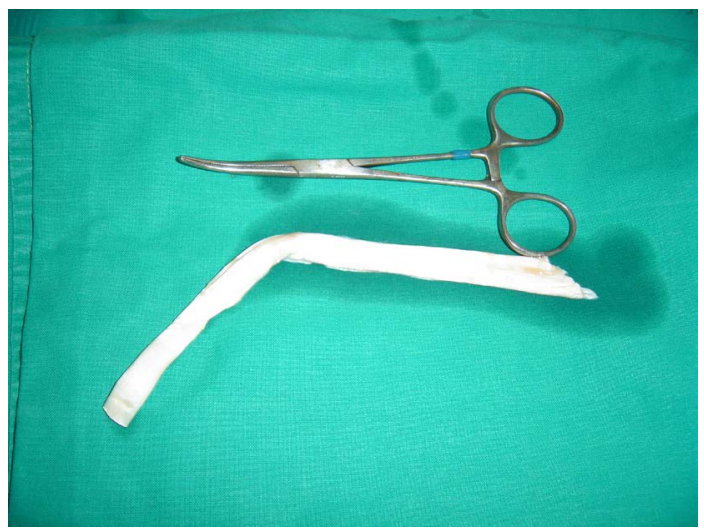

Figure 3. Freeze dried Achilles tendon allograft.

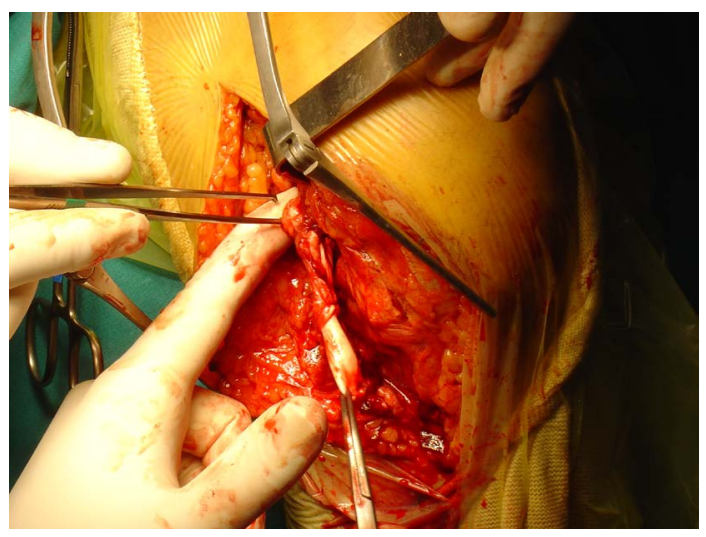

Figure 4. Graft shaped and weaved through MCL.

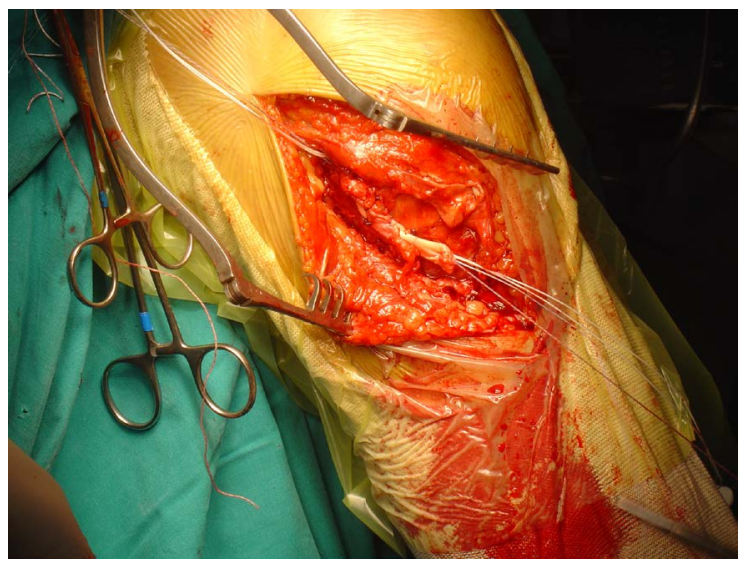

Figure 5. Postero-medial capsule repaired. Graft-ligament construct re-attached to femur and tibia with bone anchor sutures.

A dynamic knee splint was applied locked in 20 degrees of flexion for three weeks, then allowing flexion between 20 - 90 degrees for two weeks and free motion for two more weeks.

The splint was then removed and a muscle-strengthening program was followed for one month. 
About two months postoperatively the patient returned to his previous activities including heavy manual work. On final follow-up one year postoperatively the knee was medially stable with a slight anterior laxity and completely pain-free.

\section{Discussion}

"The supporting structures on the medial side of the knee consist of a superficial fascial layer, a deep capsular layer with the deep medial collateral ligament in it and in between the superficial medial collateral ligament" [1] [2].

"While it is generally accepted that most partial and isolated medial collateral ligament injuries can be treated non-operatively, ideal treatment of the MCL in multi-ligament knee injuries remains controversial [3] [4]. In such cases existing data support both conservative and surgical management" [4].

There are papers that clearly support surgical treatment of the ACL and non-operative treatment of the torn MCL [5] [6]. Other authors though, present series where Grade III injuries of the MCL were repaired regardless of the existence or not of concomitant injuries (posteromedial capsule, ACL, PCL, mensci, tibial plateux fracture) and report serious improvement of pain and instability [7]. Gorin et al. [8] report on a case of ACL and MCL tear. During surgery and after the ACL was repaired, medial stability was assessed and no improvement was found so they proceeded to primary repair of the MCL, achieving an excellent final result.

We believe that in cases with gross medial or worse postero-medial knee instability primary surgical exploration and repair or reconstruction is justified but above all it is a logical thing to do. ACL reconstruction can always be performed arthroscopically at a second stage, on a quiet and much more stable knee. One should also remember that not all cases of ACL injury require surgical reconstruction after a good rehabilitation program.

Unfortunately severe MCL damages are often difficult to repair directly. Various techniques have been proposed for its reconstruction including quadriceps tendon free graft augmentation [9], autologous bone-patella tendon-bone or semi tendinosous graft [7] [10], gracilis tendon autograft [8], transposition of great adductor muscle tendon [11] etc. All these techniques appear to work well but obviously carry the disadvantages of further (and sometimes extensive) surgical dissection, donor site morbidity and prolonged surgical time under tourniquet.

Tendon allografts have been routinely used in ACL repair for long. They incorporate quickly and do well in long term follow ups. Good overall results have been reported with the use of Achilles tendon allografts [12]. The Pulvertaft weave technique is also a well known and time honored technique for strong tendon repairs. The technique was originally described for tendon transfers in the upper limb but has already been used in the lower limb with equally good results [13]. Finally bone anchors are extensively used for osteoligamentous injuries and their usefulness in MCL repair has already been described [14]. So the combination though not previously reported had a sound surgical basis and worked well in our patient. 


\section{Conclusion}

Conclusively, we believe that augmentation of the severely damaged MCL with a tendon allograft using the Pulvertaft weave, combined with bone anchor sutures for bony stabilization of the construct, offer a strong and reliable repair and we strongly recommend it.

\section{Statement}

Publication of this paper has the full consent of the patient presented.

\section{References}

[1] Wijdicks, C.A., Griffith, C.J., Johansen, S., Engbretsen, L. and La Prade, R.F. (2010) Injuries to the Medial Collateral Ligament and Associated Medial Structures of the Knee. The Journal of Bone and Joint Surgery. American Volume, 92, 1266-1280. http://dx.doi.org/10.2106/JBJS.I.01229

[2] Wymenga, A.B., Kats, J.J., Koloos, J. and Hillen, B. (2006) Surgical Anatomy of the Medial Collateral Ligament and the Posteromedial Capsule of the Knee. Knee Surgery, Sports Traumatology, Arthroscopy, 14, 229-234. http://dx.doi.org/10.1007/s00167-005-0682-1

[3] Kovachevich, R., Shah, J.P., Arens, A.M., Stuart, M.J., Dahm, D.L. and Levy, B.A. (2009) Operative Management of the Medial Collateral Ligament in the Multi-Ligament Injured Knee: An Evidence Based Systematic Review. Knee Surgery, Sports Traumatology, Arthroscopy, 17, 823-829. http://dx.doi.org/10.1007/s00167-009-0810-4

[4] Miyamoto, R.G., Bosco, J.A. and Sherman, O.H. (2009) Treatment of Medial Collateral Ligament Injuries. Journal of the American Academy of Orthopaedic Surgeons, 17, 152-161. http://dx.doi.org/10.5435/00124635-200903000-00004

[5] Halinen, J., Lindahl, J. and Hirvensalo, E. (2009) Range of Motion and Quadriceps Muscle Power after Early Surgical Treatment of Acute Combined Anterior Cruciate and Grade-III Medial Collateral Ligament Injuries. A Prospective Randomized Study. The Journal of Bone and Joint Surgery. American Volume, 91, 1305-1312. http://dx.doi.org/10.2106/JBJS.G.01571

[6] Pressman, A. and Johnson, D.H. (2003) A Review of Ski Injuries Resulting in Combined Injury to the Anterior Cruciate Ligament and Medial Collateral Ligament. Arthroscopy, 19, 194-202. http://dx.doi.org/10.1053/jars.2003.50054

[7] Chen, Y., Yu, F., Zhu, Y., Huang, G. and Zhang, C. (2009) Reconstruction of Knee Medial Collateral ligaments. Zhongnan Daxue Baoyixueban, 34, 109-114.

[8] Gorin, S., Paul, D.D. and Wilkinson, E.J. (2003) An Anterior Cruciate Ligament and Medial Collateral Ligament Tear in a Skeletally Immature Patient: A New Technique to Augment Primary Repair of the Medial Collateral Ligament and an Allograft Reconstruction of the Anterior Cruciate Ligament. Arthroscopy, 19, E21-E26.

[9] Jung, K.A., Lee, S.C., Hwang, S.H. and Jung, S.H. (2009) Quadriceps Tendon Free Graft Augmentation for a Midsubstance Tear of the Medial Collateral Ligament during Total Knee Arthroplasty. Knee, 16, 479-483. http://dx.doi.org/10.1016/j.knee.2009.04.007

[10] Bosworth, D.M. (1952) Transplantation of the Semitendinosus for Repair of Laceration of Medial Collateral Ligament of the Knee. The Journal of Bone and Joint Surgery. American Volume, 34, 196-202.

[11] Zhong, G.W., Xu, D.C. and Yan, Y. (2001) Repair of Medial Collateral Ligament Defect of 
Knee Joint with Transposition of Great Adductor Muscular Tendon Pedicled Vessels. Zhongguo Xiufu Chongjian Waike Zazhi, 15, 153-154.

[12] Shah, A.A., McCulloch, P.C. and Lowe, W.R. (2010) Failure Rate of Achilles Tendon Allograft in Primary Anterior Cruciate Ligament Reconstruction. Arthroscopy, 26, 667-674. http://dx.doi.org/10.1016/j.arthro.2010.02.031

[13] Rath, S., Schreuders, T.A. and Selles, R.W. (2010) Early Postoperative Active Mobilization versus Immobilization Following Tibialis Posterior Tendon Transfer for Foot-Drop Correction in Patients with Hansen's Disease. Journal of Plastic, Reconstructive \& Aesthetic Surgery, 63, 554-560. http://dx.doi.org/10.1016/j.bjps.2008.11.095

[14] Xiu, X.G., Zhang, S.P., Deng, N., Cao, B., Yang, Z.L. and Chen, X.F. (2009) Repair of Medial Collateral Ligament Ruptures of the Knee with Suture Anchor. Zhongguo Gushang, 22, 588589.

\section{Submit or recommend next manuscript to SCIRP and we will provide best service for you:}

Accepting pre-submission inquiries through Email, Facebook, LinkedIn, Twitter, etc. A wide selection of journals (inclusive of 9 subjects, more than 200 journals)

Providing 24-hour high-quality service

User-friendly online submission system

Fair and swift peer-review system

Efficient typesetting and proofreading procedure

Display of the result of downloads and visits, as well as the number of cited articles

Maximum dissemination of your research work

Submit your manuscript at: http://papersubmission.scirp.org/

Or contact ojo@scirp.org 